\title{
A Case-Based Quality Assurance System for Higher Education
}

\author{
Putsadee Pornphol and Suphamit Chittayasothorn
}

\begin{abstract}
The current rapid-changing developments in computer and information technology continue to make the world appear much smaller; communication methods in every field become easier, faster, and more convenient. Evidently, education systems are a clear example of these changes learners can study at the desired institute despite physical distance between the student and facility. In particular, curricula development is of utmost importance and should be credible and acceptable within the labor market to determine whether graduates of each course are truly knowledgeable and skilled. Thailand's Office of the Higher Education Commission has established the Thai Qualifications Framework for Higher Education (TQF: HEd) as accreditation standards to ensure acceptance of higher education quality in Thailand. This paper presents case-based reasoning for advisory systems and recommendations for users within computer curriculum development according to the Thai qualifications framework for higher education (TQF: HEd) which covers knowledge development in 5 areas i.e. 1) Ethics and Morality 2) Knowledge Development 3) Intellectual Development 4) Interpersonal Relationship and Responsibility and 5) Numerical Analysis, Communication, and Information Technology Skills. The purpose is to empower curricula developers with capabilities to determine the direction of course development.
\end{abstract}

Index Terms-Advisory system, case-based reasoning, TQF.

\section{INTRODUCTION}

Qualifications Framework for Higher Education (TQF: HEd) explicitly outlays the Thai higher education system, subject matter allocation, progressive outcome standards and subject volume for each level in alignment with required length of time, course description and characteristics of each level, and further opportunity for transfer and equivalency of items learned by experience to promote lifelong learning, including systems and mechanisms that ensure confidence in the effectiveness of implementation according to the Thai qualifications framework for higher education to determine capability to produce graduates that achieve standards of quality.

The importance of the Thai qualifications framework for higher education is as follows: 1) As a tool to implement policies aimed at development of quality and standards for education measurement as set forth under the Thai National

Manuscript received August 25, 2016; revised December 23, 2016.

Putsadee Pornphol is with Phuket Rajabhat University, Faculty of Science and Technology, Phuket, Thailand (e-mail: proud.cs.pkru@gmail.com).

Suphamit Chittayasothorn was with King Mongkut's Institute of Technology Ladkrabang, Faculty of Engineering, Bangkok, Thailand (e-mail: suphamit@kmitl.ac.th).
Education Act concerning higher education standards and quality assurance leading to properly defined conduct within the education institute 2) Focus on Learning Outcomes and minimum quality standards to ensure the quality of graduates 3) Aimed at processing various regulations and guidelines relevant to the curriculum and include interconnect methods of instruction as the same matter 4) As an efficient communication tool to foster understanding and confidence among relevant parties / stakeholders i.e. students, parents, operators, communities, society, and various institutions both local and overseas - regarding desired features of graduates 5) Aimed at gaining acceptance for certification or degrees issued by education institutes in Thailand and equivalency with higher education institutes - both local and overseas - and offer diverse opportunity for higher education institutes to manage curricula and methods of instruction albeit confident in the quality of graduates to attain desired learning outcome standards and capable to happily and proudly undergo professions at the satisfaction of employers 6) Promote lifelong learning. The objectives of Thai Qualifications Framework for Higher Education include: 1) To guarantee the minimum level of quality of graduates in each subject matter or degree 2) To ensure that each subject matter has sufficient self-supervision over the quality of its graduates produced and that graduates in the same subject matter within each institute surpass the minimum required levels set forth by the applicable standards 3) Aimed at deregulations and empowerment to ensure that educational institutes are fully prepared for education management [1].

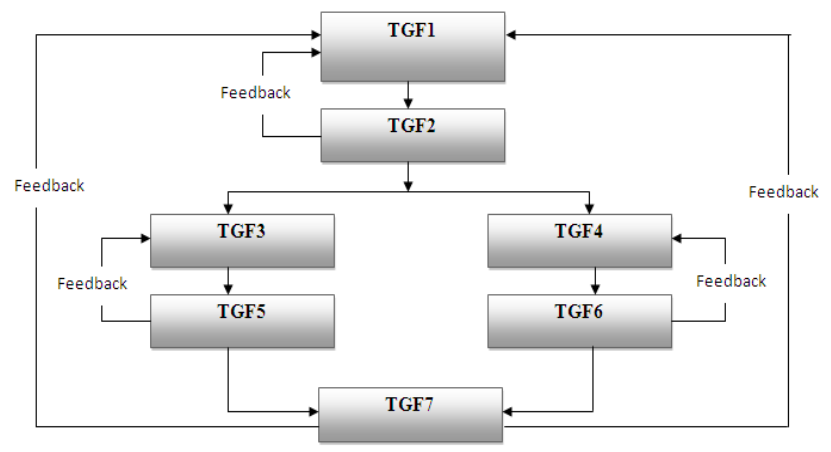

Fig. 1. TQF framework.

TQF1 sets the standards of degree obtained and is compared to a framework or structure for each subject matter; course and curricula development for each subject matter must adhere to TQF1 as applicable to each subject matter. TQF2 outlays the program specifications for each subject matter and management of instruction methods to ensure graduates achieve the learning outcome within each specified course. TQF3 includes the course specifications 
and presents data relevant to management procedures for each subject matter to ensure instruction methods are managed and aligned according to curriculum plans. TQF4 covers field experience specifications and includes data concerning management procedures for each subject matter or required internship activities, field training, or cooperative education. TQF5 provides course outcome reports and covers management of instruction provided by each teacher within each subject matter; upon completion of the term, details obtained will represent the overall picture of instruction and learning management within the subject and determine effectiveness of instruction coverage and execution of plans. TQF6 generates field experience reports that indicate the outcome of internship, field training, or cooperative education to determine achievement of goals and plans or otherwise. TQF7 includes annual program reports by the curriculum and course committee [1].

\section{LITERATURE REVIEW}

As the present form and design of higher education methods continues to change according to technological developments, learners are increasingly able to receive education from various sources without the need to physically travel to the institute. Consequently, this factor necessitates various education institutes, universities, and state agencies which supervise education in each country to adapt their strategies and education methods in alignment with a rapidly changing society.

Education quality assurance agencies have a role to process learning outcomes, determine levels of quality in each education institute, certify and accredit quality standards of education, and to search for and establish quality assurance models for application within education institutes to determine the levels of education quality.

TQM (Total Quality Management) is a management method that creates quality assurance models and has enjoyed widespread acceptance among higher education institutes for the purpose of education quality assurance in many countries and regions i.e. Africa, China, Southeast Asia, UK, Australia, and New Zealand etc. [2] especially during the late 1980 s to the 1990s before ISO9000 was introduced in 2003 [3] which is considered the universal standard for higher education applied in European countries for education quality assurance [4]. ISO has been widely accepted as it encourages users to possess knowledge of preparation either from knowledge sources or recommendations directly provided by capable individuals or teams, or from existing online data services, including user manuals, videos, various file formats i.e. MS-Word, MS-PowerPoint, PDF etc. [5] that help users feel assisted by experts available at all times [6].

Education Quality Assurance in Thailand began in 2002 when the Thai government launched the higher education standard framework concept under responsibility of the Office of the Higher Education Commission to research the topic of standard framework for higher education and study conceptual framework for desired features of graduates, development of graduate features, production processes, and development of standard framework for degrees and producing graduates to ensure Thai education achieves standards acceptable at the international level. Implementation is divided into 2 phases. Phase 1: During 2003 - 2006, a collaboration of Thai education experts and Australian higher education quality assurance specialists jointly created the National Qualifications Framework for Higher Education in Thailand [7]. Phase 2: During 2006 2009, further development of the National Qualifications Framework aligned implementation with cultural features to ensure levels of quality acceptable at the international level. In 2009, the Office of the Higher Education Commission announced for all higher education institutes to apply the Thai Qualifications Framework for Higher Education [7].

Office of the Higher Education Commission is the primary agency responsible and has arranged numerous meetings, to provide information on the Thai Qualifications Framework for Higher Education, to promote understanding among relevant individuals and agencies pertaining to the various processes and purposes. Additional information is provided via the agency's website to outline each type of standard qualifications framework [7]. Each higher education institute has its own quality assurance agency with a duty to propose recommendations and invite expert trainers to provide knowledge accordingly. Various education institutes have developed internal information systems to store or manage the Thai Qualifications Framework for Higher Education [1]. Nevertheless, the problems faced by Thailand in regards to application of the framework include lack of experts and insufficient data or manuals, especially course and curriculum development which is considered a key component that reflects features of graduates in each subject matter.

Various software applications have been developed as an alternative for course and curriculum development, implementation, and to support the work of relevant parties i.e. instructors, teachers, students etc. For example, Curriculum 21[8] is an online software application developed for convenient curriculum preparation and to provide opportunities to users in each field to develop or add details; Curriculum Mapping tools under the Indiana Department of Education [9] , TODCM [10] Curriculum Mapping System is an Open Source Software which enables users to perform Curriculum Mapping as desired; Curriculum TRAK [11] is a software which assists and enables relevant parties to manage courses and curricula, is available in various languages, and has functions that support the work of teachers and students alike; WIDS (Worldwide Instruction Design System) [12] has similar functions to other aforesaid software and enables users to collect and manage course and curriculum data; NVio (QRS NUD*IST) [13] is a course and curriculum management application which includes Curriculum Mapping for each subject matter, subject objectives, and performance evaluation.

In summary, the aforementioned curriculum management software allows users to specify courses which have already been designed or users may alternatively design their own models; moreover, the software supports other relevant parties i.e. teachers and students and generates reports to support decision-making among curriculum managers.

Modeling Total Quality Management in Higher Education with case-based reasoning [14] is a research work that 
applies Care-Based Reasoning to quality assurance at the higher education level in Malaysia and records case studies of actual instruction provided within each subject to further improve standards.

\section{CASE-BASED REASONING (CBR) OF THE TQF ADVISORY SYSTEM}

Case-based reasoning is a methodology that applies past experience gained or past events as a guide for problem-solving in the present [15]. Case-based reasoning life cycle is comprised of 4 primary stages [16] i.e. 1) Retrieve searches for stored cases and determines whether the case is applicable to solving the problem at hand 2) Reuse applies the case from stage 1 to solve the problem at hand 3) Revise amends or adapts the problem-solving methods for optimal application to the problem at hand and 4) Retain keeps and records the solution methods applied to the new problem for additional case-based purposes.

Fig. 2 illustrates the lifecycle and inherent details within case-based reasoning as applied to curriculum development. Initially, curriculum developers should specify the terms, conditions, parameters, and domain variables according to the desired subject whereupon the terms, conditions, and domain variables are calculated to identify similarities among cases stored in case-based records. Cases with the highest similarity values or closest to 1 [17] [18] are considered the optimal solution to the user and should be further applied to decision-making. Nevertheless, if the user is unsatisfied with the case obtained, the user specify new terms, conditions, parameters, and domain values until the user is satisfied with the case obtained. When the user applies the case obtained according to the problem at hand, a new case emerges and is further stored in case-based records.

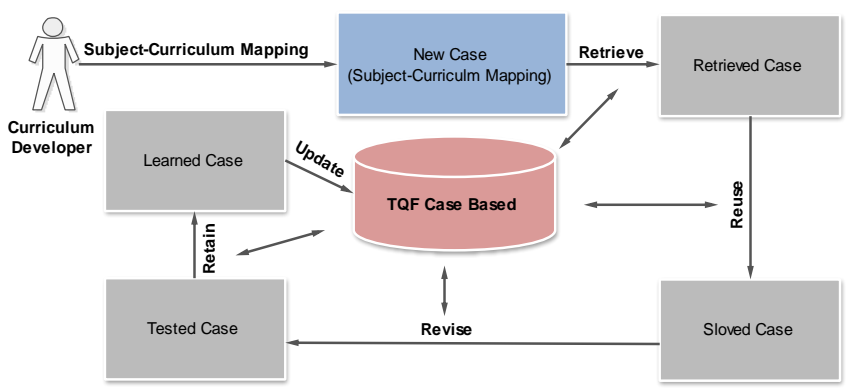

Fig. 2. TQF-CBR component/cycle.

\section{A. Similarity Values between Attribute Values of New Cases and Attribute Values of Old Cases}

Parameters or Attributes within this system are divided according to 5 areas of learning development set forth under TQF1 in Computer Subject by the Office of the Higher Education Commission i.e. 1) Ethics and Morality 2) Knowledge Development 3) Intellectual Development 4) Interpersonal Relationship and Responsibility and 5) Numerical Analysis, Communication and Information Technology Skills whereas the values applied to benchmark each parameter or attributes are comprised of "Primary Responsibility", "Secondary Responsibility", and "Not Responsible".

TABLER I: SimILARITY, $\mathrm{S}_{\mathrm{A}}$ BETWEEN ATTRIBUTE VALUES

\begin{tabular}{|l|c|c|c|c|}
\hline \multirow{4}{*}{ Attribute Value in new case } & \multicolumn{3}{|c|}{ Attribute Value in ole case } \\
\cline { 2 - 5 } & & Primary Responsibility (PR) & Primary Responsibility (PR) & Not Responsible (NR) \\
\cline { 2 - 5 } & Primary Responsibility (PR) & 1 & 0.5 \\
\cline { 2 - 5 } & Secondary Responsibility (SR) & 0.5 & 0 & 0.25 \\
\cline { 2 - 5 } & Not Responsible (NR) & 0 & 0.25 \\
\hline
\end{tabular}

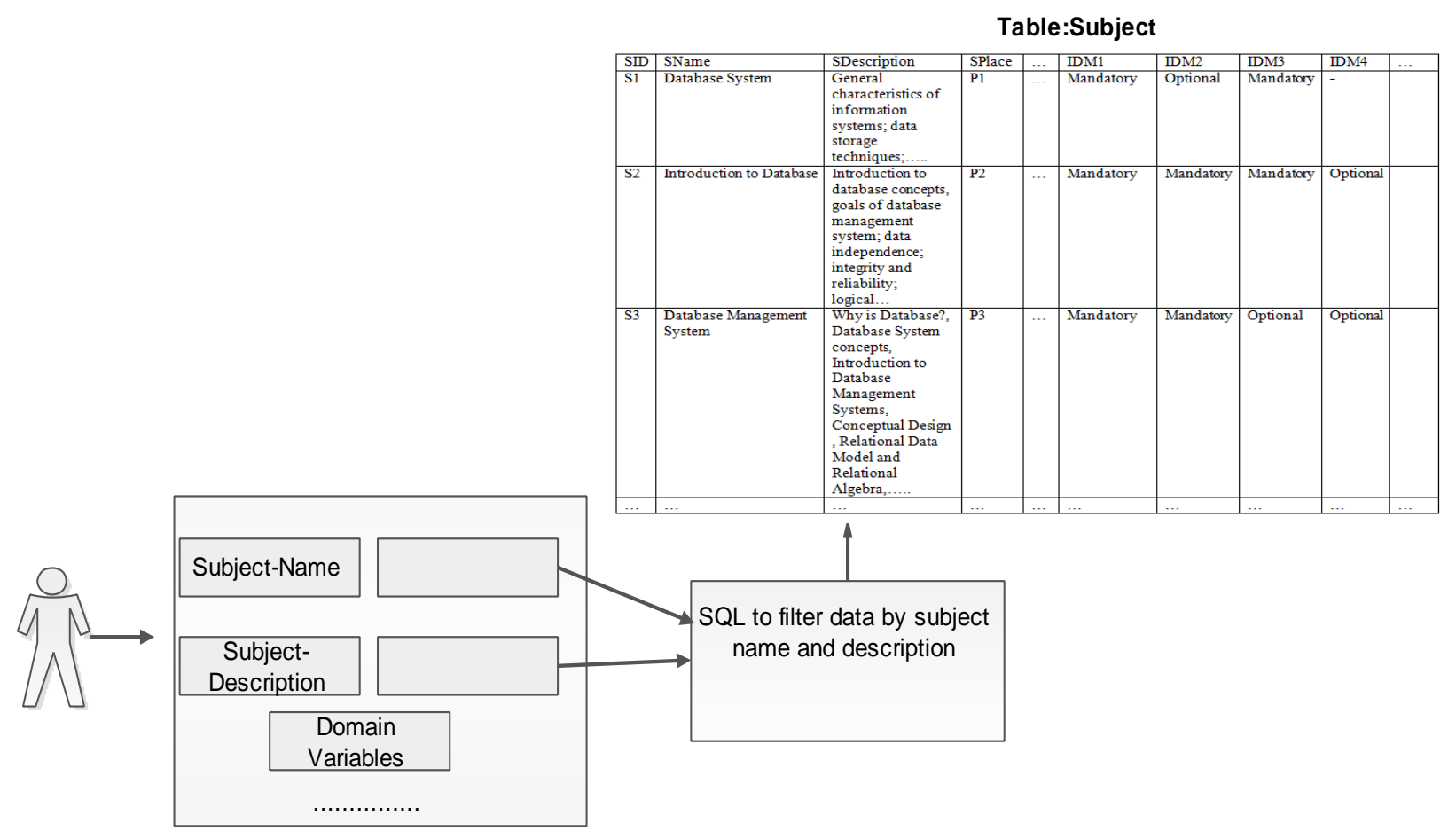

Fig. 3. SQL commands and subject data filters according to name and course description. 
Table I depicts the similarity values between attribute value of new cases and attribute value of old cases according to knowledge development in each area within each subject as indicated above.

Fig. 3 illustrates use of SQL (Structure Query Language) commands to filter data by subject name and description in new case from old cases stored in the database and comparison of curriculum mapping for learning within each area between all new cases and old cases obtained from the aforementioned filter. Domain Variables are depicted in Fig. 4.

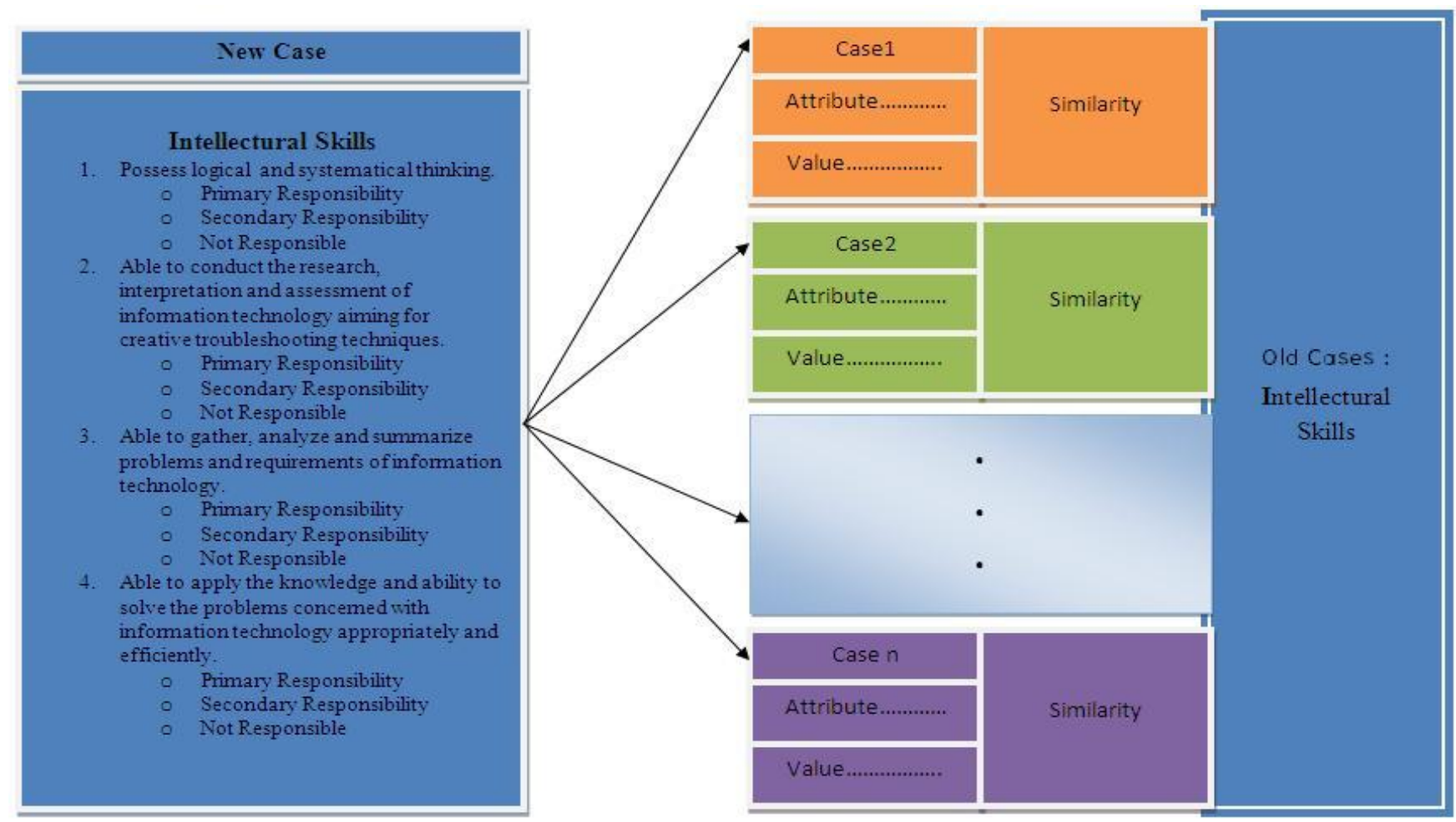

Fig. 4. Comparison between attribute values of new cases and old cases.

Fig. 4 illustrates a comparison between learning development values and problem-solving skills between one new case and all existing old cases as specified in the new case to calculate similarity values for each attribute by application of Table 1 values. For example, if new case attributes appear as "Primary Responsibility" and when compared with old cases, i.e. Case 1, if the attribute is "Primary Responsibility", the similarity value of this attribute would be "1" and so forth.

\section{B. Formula Applied to Calculate Similarity Values}

All of the $n$ attributes are used to determine the overall case similarity. Therefore, if these attributes are designated as $a_{1}-a_{n}$, and if the similarity for each ai is $S(a i)$, the overall similarity $\mathrm{S}$ is specified as (1).

$$
\mathrm{S}=\sum_{i=1}^{n} \frac{S(a i)}{n}
$$

Next, if we assign a weighting, Wi to each ai, the revised similarity, S', now becomes as specified in (2)

$$
\mathrm{S}=\sum_{i=1}^{n} \frac{(W i)((s(a i))}{\sum_{i=1}^{n} W i}
$$

Note that the default weighting is 1 .

To find the Similarity Value of courses, when all 5 learning areas are considered according to (1) and (2)

$$
\mathrm{S}_{\text {subject }}=\sum_{i=1}^{5} \frac{S(i)}{5}
$$

and

Note that the default weighting is 1

$$
\mathrm{S}_{\text {subject }}=\sum_{i=1}^{5} \frac{(W i)(s(i)}{\sum_{i=1}^{5} W i}
$$

And to find the Similarity Value of curriculum is shown in (4) and (5)

and

$$
\mathrm{S}_{\text {curriculum }}=\sum_{i=1}^{n} \frac{(W i)\left(S_{\text {subject }}(i)\right.}{\sum_{i=1}^{n} W i}
$$

Note that the default weighting is 1 .

Fig. 5 illustrates similarity values obtained from 5 areas of learning development within a single subject including new and old cases of the same subject. In summary, the new case has overall similarity with case 3 at similarity = 0.76875 however similarity in each area of development is further calculated as follows:

- Ethics and Morality is similar to case 1 at similarity = 0.75 .

- Knowledge Development is similar to case 2 at similarity $=0.71875$.

- Intellectual Development is similar to case 3 at similarity $=0.875$ 
- Interpersonal Relationship and Responsibility is similar to case 3 at similarity $=1$.
- Numerical Analysis, Communication, and Information Technology Skills is similar to case 3 at similarity $=0.875$.

C. Matching Case Report

\begin{tabular}{|c|c|c|c|c|c|c|c|}
\hline \multirow{2}{*}{$\begin{array}{c}\text { kn owled ge Development } \\
\text { 1. E thics and Morallity }\end{array}$} & \multirow[b]{2}{*}{ New Cas } & \multicolumn{3}{|c|}{ Old Cases } & \multicolumn{3}{|l|}{ Similarity } \\
\hline & & Casel & $\mathrm{Case2}$ & $\mathrm{Case}_{3}$ & NenCase Casel & NenCase: Case2 & NewCase: Case3 \\
\hline 1.1 Recognize the valve of morals, ethics, devotion and honesty. & SR & $\mathrm{SR}$ & $\mathrm{SR}$ & $\mathrm{NR}$ & 1 & 1 & 0.25 \\
\hline 1.2Maintain high s df-discipline, punctuality and responsibility for own sake and the sake of the society. & $\mathrm{PR}$ & $\mathrm{SR}$ & $\mathrm{PR}$ & $\mathrm{SR}$ & 0.5 & 1 & 0.5 \\
\hline 1.3Possess desirable laadership and fellowship. & $P R$ & $P R$ & $\mathrm{PR}$ & $\mathrm{SR}$ & 1 & 1 & 0.5 \\
\hline 1.4Res pect the rights and lis ten to comments of others, with consideration of misman dignity. & $8 R$ & $\mathrm{SR}$ & $\mathrm{NR}$ & $\mathrm{SR}$ & 1 & 0.25 & 0.5 \\
\hline 1.5Pursva the rules and regulations agreed by the crganization and the sociery. & $\mathrm{SR}$ & $P R$ & $\mathrm{PR}$ & SR & 0.5 & 0.5 & 1 \\
\hline 1.6. Able to evabate possible impacts on the vse of compu ter that may cayse to individual, org anization and conr & $\mathrm{PR}$ & $\mathrm{NR}$ & $S R$ & $\mathrm{NR}$ & 0.25 & 0.5 & 0.25 \\
\hline \multirow[t]{3}{*}{1.7 Possess both academic and profess sicnal morality. } & $S R$ & $\mathrm{SR}$ & $\mathrm{RR}$ & $\mathrm{PR}$ & 1 & 0.5 & 0.5 \\
\hline & 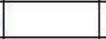 & & & & 0.75 & 0.678571429 & 0.5 \\
\hline & & & & & 0.75 & 0.678571429 & 0.5 \\
\hline & \multicolumn{3}{|c|}{ Old Cases } & & Similarity & & \\
\hline 2. Know ledge Development & New Case & Case1 & Case 2 & Case3 & NewCase:Casel & New Case: Case 2 & New Case:Case3 \\
\hline 2.1 Possess good knowledge and clear understanding in theoretical essence of studying contexts. & PR & PR & PR & PR & 1 & 1 & 1 \\
\hline 2.2.Able to assess problems, undentand technical contexts and clarify the requirements in information technolos: & SR & SR & PR & PR & 1 & 0.5 & 0.5 \\
\hline 2.3.Able to procesd with analysis, design, installation and development of information technologycomplied with & SR & SR & SR & PR & 1 & 1 & 0.5 \\
\hline 2.4 Able to tack the ad iancement of academic theories and the evolution of information technology. & $\mathrm{SR}$ & $\mathrm{SR}$ & $\mathrm{SR}$ & SR & 1 & 1 & 1 \\
\hline 2.5 Possess dear understanding and keen interest in information technologyknow led ge on a consistent basis. & SR & $\mathrm{NR}$ & $\mathrm{SR}$ & NR & 0.25 & 0.25 & 0.25 \\
\hline 2.6 Have broad knowledge in the field of study to ensure promptness for possible changes and technological imm & SR & $\mathrm{NR}$ & SR & SR & 0.25 & 1 & 1 \\
\hline |2.7 Experienced in developing and applying softw are prog rams for practical use. & $\mathrm{SR}$ & $\mathrm{NR}$ & SR & PR & 0.25 & 1 & 0.5 \\
\hline \multirow{3}{*}{2.8 Advance the knorledge integration to be applied to other related felds of s tudy. } & PR & PR & PR & PR & 1 & 1 & 1 \\
\hline & & & & & 0.59375 & 0.71875 & 0.59375 \\
\hline & & & & & 0.59375 & 0.71875 & 0.59375 \\
\hline & \multicolumn{3}{|c|}{ OldCases } & & Similarity & & \\
\hline 3. Intellectural Skills & New Case & Casel & Case 2 & Case3 & NewCase:Casel & New Case: Case2 & New Case:Case 3 \\
\hline 3.1. Possess logical and systematical thinking. & PR & PR & SR & PR & 1 & 0.5 & 1 \\
\hline $3.2 \mathrm{Able}$ to conduct the ras arch, interpretation and assessment of information technology aiming for castive tro & PR & SR & SR & PR & 0.5 & 0.5 & 1 \\
\hline 3.3 Able to gather, analyze and summarize problems and requirements of information technology. & SR & $\mathrm{NR}$ & PR & $\mathrm{SR}$ & 0.25 & 1 & 1 \\
\hline 3.4 Able to aply the lnowledge and ability to solve the problems concerned with information technology approf & PR & SR & $\mathrm{PR}$ & SR & 0.5 & 0.5 & 0.5 \\
\hline & \multicolumn{4}{|c|}{$s$} & 0.5625 & 0.625 & 0.875 \\
\hline \multicolumn{5}{|l|}{ s } & 0.5625 & 0.625 & 0.875 \\
\hline & \multicolumn{3}{|c|}{ Old Cases } & & Similarity & & \\
\hline 4. Interpersonal Skills and Responsibility & New Case & Casel & Case2 & Case 3 & NewCase:Casel & New Case:Case? & New Case:Case 3 \\
\hline 4.1. Able to prodves vebal and written communication in Thai and other foregn langu ages effectively wit th sever & SR & SR & SR & SR & 1 & 1 & 1 \\
\hline 4.2 Provide assistance to others to tackle a cettain problem with leadership of fellowship depending on the sitvat & PR & SR & PR & PR & 0.5 & 1 & 1. \\
\hline 43 Able to make vse of know ledge acquired from the field of study to lad the society to the accurate direction. & $\mathrm{PR}$ & $\mathrm{PR}$ & NR & PR & 1 & 1 & 1 \\
\hline 4.4 Possess high responsibility in both personal and group wotks. & PR & SR & PR & PR & 0.5 & 1 & 1. \\
\hline 4.5 Able to be an initiator to present ideas in dealing with certain circums tances while expressing the s tandpoint & $\mathrm{SR}$ & SR & $\mathrm{NR}$ & SR & 1 & 0.25 & 1. \\
\hline 4.6 Responsible for the derelopment of personal know ledge and acad erric adiancement. & SR & SR & SR & SR & 1 & 1 & 1 \\
\hline \multicolumn{5}{|l|}{ s } & 0.833333333 & 0.875 & 1 \\
\hline \multicolumn{5}{|l|}{ s } & 0.833333333 & 0.875 & 1 \\
\hline & \multicolumn{3}{|c|}{ OldCases } & & Similarity & & \\
\hline 5. Numerical Analysis, Communication and Information Technology Skills & New Case & Casel & Case 2 & Case 3 & NewCase:Casel & New Case:Case? & NewCase:Case 3 \\
\hline 5.1 Be professional in making use of technical devices required for the vse of information technology. & PR & SR & SR & $\mathrm{PR}$ & 0.5 & 0.5 & 1 \\
\hline 5.2 Able to offer procivetive suggestions to solve a problem with the creative application of mathematical inform & SR & SR & $\mathrm{NR}$ & SR & 0.25 & 0.25 & 1 \\
\hline $53 \mathrm{Able}$ to communicate in verbal and written forms effectively with the apropriate selection of media sources. & SR & SR & SR & SR & 1 & 1 & 1 \\
\hline \multirow[t]{7}{*}{ 5.4 Able to use infomation technology for communication appropriately and efficiently. } & PR & PR & $\mathrm{PR}$ & SR & 1 & 1 & 0.5 \\
\hline & \multicolumn{4}{|c|}{5} & 0.6875 & 0.6875 & 0.875 \\
\hline & \multicolumn{4}{|c|}{ 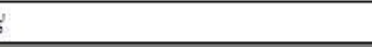 } & 0.6875 & 0.6875 & 0.875 \\
\hline & & & & & Similarity & & \\
\hline & & & & & NewCase:Casel & New Case:Case2 & New Case:Case 3 \\
\hline & & & & S-subject & 0.685416667 & 0.716964286 & 0.76875 \\
\hline & & & & s-subject & 0.685416667 & 0.716964286 & 0.76875 \\
\hline
\end{tabular}

Fig. 5. An example of obtaining similarity values according to the five areas of learning development within one subject. 


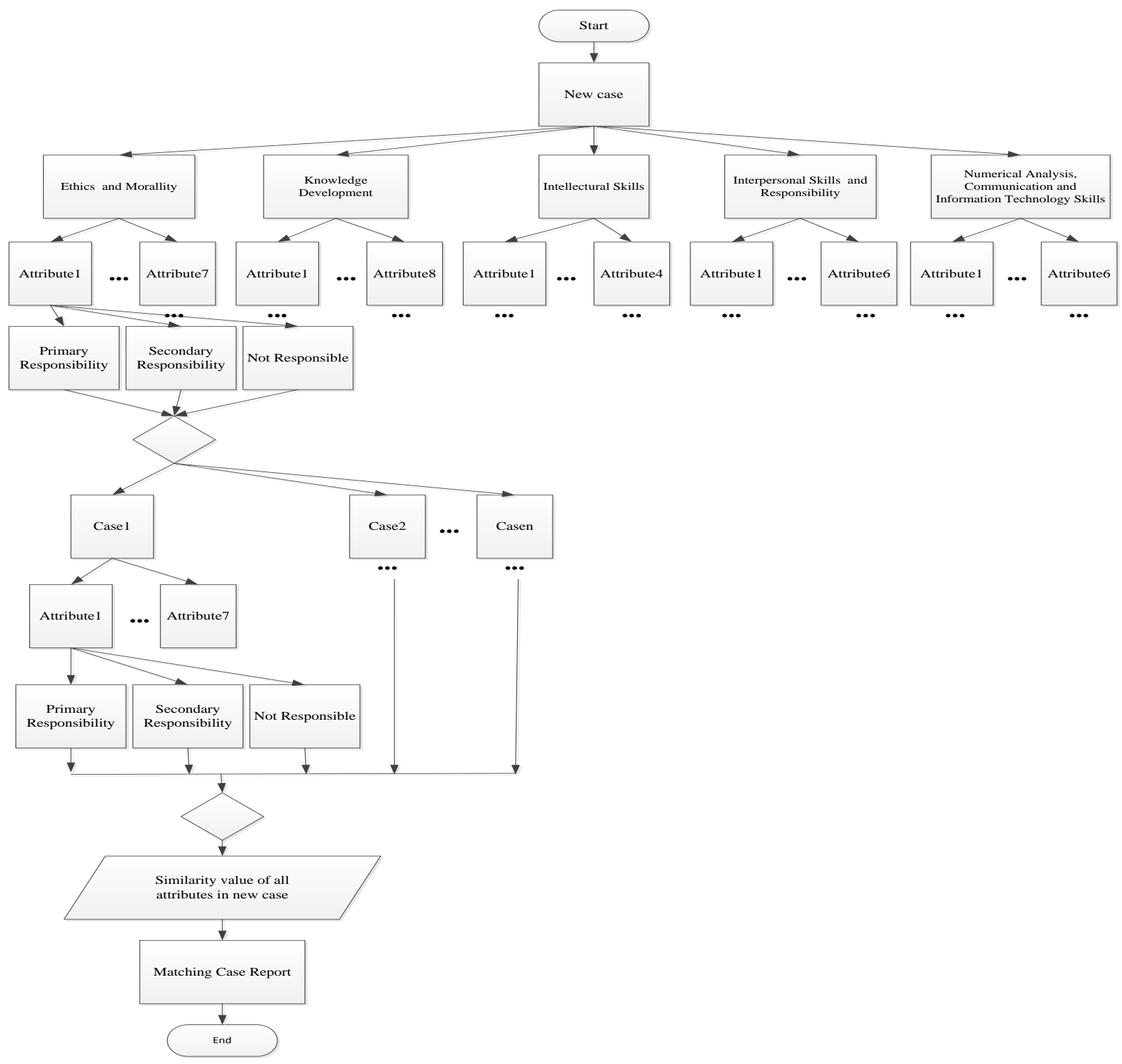

Fig. 6. Similarity search and matching case report processing.

An actual example of one of the rules for matching cases is:

\section{rule cxMatchingMCase1}

if

the cxResultCase 1 of cxSmCase $1>$ the cxResultCase 2 of cxSmCase 2 and the cxResultCase 1 of cxSmCase $1>$ the cxResultCase 3 of cxSmCase 3 and

the cxResultCase 1 of cxSmCase $1>$ the cxResultCase 4 of cxSmCase 4 and

the cxResultCase 1 of cxSmCase $1>$ the cxResultCase 5 of cxSmCase 5 and

the cxResultCase 1 of cxSmCase $1>$ the cxResultCase 6 of cxSmCase 6 and

the cxResultCase1 of cxSmCase $1>$ the cxResultCase7 of cxSmCase7

then the cxMatching of cxGetMatching become case 01 .

\section{BENEFIT OF CASE-BASED REASONING TOWARD CURRICULUM DEVELOPMENT ADVISORY SYSTEM}

The advantages of case-based reasoning are mentioned in various research papers as applicable to information technology development [19] for example, 1) As a process to determine how previous work was completed 2) Easier work because of available past data as reference 3) Easier system administration. Therefore, application of case-based reasoning to develop advisory systems for curriculum development would assist curriculum developers to know what type of graduate the course will produce according to the 5 areas of development and whether the overall curriculum is similar to other courses or otherwise.

\section{CONCLUSION}

Advisory System proposes problem-solving methods to users for decision-making purposes; this system is a form of suggestion as opposed to providing an answer and may include multiple suggestions. Advisory System differs from expert systems for example, advisory systems suggest, as opposed to inform, viable solutions to users while expert systems clearly specify problem-solving methods. Additionally, a key difference between advisory and expert systems is that advisory systems apply case-based reasoning methodology while expert systems provide rule-based reasoning. The objective of applying advisory systems to 
computer course developers in accordance with qualifications framework for higher education is to ensure that course developers have a system which recommends how computer course graduates would gain all 5 areas of learning i.e. 1) Ethics and Morality 2) Knowledge Development 3) Intellectual Development 4) Interpersonal Relationship and Responsibility and 5) Numerical Analysis, Communication, and Information Technology Skills.

\section{REFERENCES}

[1] P. Pornphol and C. Saejueng, "The information technology for Thai qualifications framework for higher education," in Proc. the Fifth Asian Conference on Education 2013 (ACE2013) \& The First Asian Conference on Society, Education and Technology 2013 (ACSET2013), Osaka, Japan, 2013.

[2] B. MED. Cosmetic Surgery in Thailand. [Online]. Available: http://www.cosmeticsurgerythailand.com/.

[3] Mymedholiday. Thailand's medical tourism statistics: A look at the international patient numbers. [Online]. Available: http://www.mymedholiday.com/blog/2013/10/793/thailands-medical-t ourism-statistics-a-look-at-the-international-patient-numbers/

[4] ThaiWebsite. Tourism statistics Thailand 2000-2014. [Online] Available: http://www.thaiwebsites.com/tourism.asp

[5] ISO. Guider to ISO IT applications. [Online]. Available: http://isotc.iso.org/livelink/livelink/fetch/2000/2122/5156198/custom view.html?func=1l\&objId=5156198\&objAction=browse\&sort=name

[6] ISO. IT tools for standards development. [Online]. Available: http://www.iso.org/iso/home/standards_development/resources-for-te chnical-work/iso_electronic_applications.htm

[7] HEC. Thai qualifications framework for higher education. [Online]. Availale: http://www.mua.go.th/users/tqf-hed/news/news8.php

[8] Curriculum21. Curriculum maping: Technology issues and resources. [Online]. Available: http://www.curriculum21.com/pd/curriculum-mapping/archives/techn ology/

[9] IDOE, "Tools for mapping and aligning the curriculum," 2009.

[10] TODCM. Curriculum mapping system. [Online]. Available: http://todcm.org/
[11] DS. Curriculum trak service. [Online]. Available: http://www.dynamic-internet-solutions.com/services.cfm

[12] WIDS. Curriculum development software and condulting. [Online]. Available: http://www.wids.org/\#\&panel1-2_<http://www.wids.org/>

[13] J. E. Shearer, "Using qualitative software in curriculum development," Online Journal of Nursing Informatics (OJNI), vol. 12, no. 2, 2008

[14] H. M. Jani, "Modelling total quality management in higher education with case-based reasoning," Journal of Next Generation Information Technology (JNIT), vol. 3, no. 3, pp. 11, 2012.

[15] J. L. Kolodner, "An introduction to case-based reasoning," Artificial Intelligence Review, vol. 6, pp. 3-34, 1992.

[16] A. Brady, T. Menzies, O. EI-Rawas, E. Kocaguneli, and J. W. Keung, "Case-based reasoning for reducing software development effort," J.Software Engineering \& Applications, vol. 3, 2010.

[17] P. Pornphol, "A decision support system implementation of the tourism area life cycle model," Management and Information Systems, Victoria University, Melbourne, 2012.

[18] B. A. Beemer and D. A. Gregg, "Advisory systems to support decision making," Decision Support System, pp. 511-528: Berlin: Springer. 2008.

[19] F. M. Lan Watson, "Case-based reasoning: Areview," The Knowledge Engineering Review, vol. 9, no. 04, pp. 327-354, 1994.

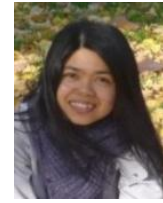

Pusadee Pornphol is an assistant professor at the Department of Computer Science, Faculty of Science and Technology, Phuket Rajabhat University, Phuket, Thailand. She received her B.S. in computer science from RU,M.S. in information technology from KMITL, Thailand and Ph.D. in information systems from Victoria University, Melbourne, Australia. Current research interests include strategic information systems in tourism and database systems.

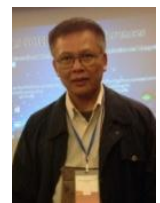

Suphamit Chittayasothorn is an associate professor at the Department of Computer Engineering, Faculty of Engineering, King Mongkut's Institute of Technology Ladkrabang (KMITL), Bangkok, Thailand. He received his B.Eng. in computer engineering from KMITL, M.Eng. in computer technology from the Asian Institute of Technology (AIT), Thailand and Ph.D. in computer science from the University of Queensland, St.Lucia, Brisbrane, Australia. His research interest is database systems. 